\title{
OPERATION FOR ENTROPION OF THE UPPER EYELID IN TRACHOMA*
}

BY

\section{T. TORGERSRUUD}

From Haile Sellassie I Hospital, Addis Ababa, Ethiopia.

IN Ethiopia, as in most oriental countries, trachoma is a very common disease, perhaps the most common of all eye diseases. There are no statistics available of its frequency among the population, but statistics from the Ophthalmic Clinic at the Haile Sellassie I Hospital show the following :

Patients attending the Ophthalmic Department (1946-1949): 5,803.

Frequency of trachoma, 2,347 cases $(40.4$ per cent.: men, 36.8 per cent.; women, $46 \cdot 8$ per cent.).

Entropion palp. sup., 490 cases $(20.8$ per cent.: men, 17.6 per cent.; women, 25.0 per cent.).

These figures show that about one person out of every five coming to hospital with trachoma has entropion of the upper eyelid. These figures may seem high, but I have the impression that the type of trachoma in Ethiopia is not too severe. Probably the number of grave cases is rather small compared with the very great morbidity. The majority of the trachoma cases-without complications-probably do not seek treatment, but are cured after some time without serious complications.

\section{Therapy}

The only possible way to treat entropion of the upper eyelid is by operation, and to tackle this task it was necessary to find a good surgical method. The recognized methods are mainly of two types : the operation from outside after Snellen-Streatfield, HotzAnagnostaki, and others, and the operation from inside after Ewing, Blaskowicz, and others. The patho-physiological fact seems to be that it is the conjunctiva and the nearest part of the tarsal plate in which the scarring process is located, which gives the entropion. This is stressed by Blaskowicz, although he is of the opinion that only the conjunctiva is subject to the shrinking process and that the tarsus does not shrink, an opinion which I cannot share as I have often found the whole tarsus enlarged to 5 or 6 times its usual thickness, which also shows that the tarsus is involved in a pathological process. I must admit that there is no correspondence between the thickness of tarsus and the degree

* Received for publication April 24, 1950. 
of entropion, as I have found very severe entropion with almost normal thickness of tarsus and vice versa, but this is probably only due to the stage in the evolution of the disease at which the operation is performed. It seems to me, therefore, that both the tarsus and the conjunctiva tarsi are involved in the process, and that they combine in giving rise to the entropion.

The technique here employed is a modification of the original Blaskowicz "inversio tarsi", founded on his patho-physiological ideas about the origin of the process. From lack of access to medical literature in this country I have had no opportunity to find out whether this procedure is new, probably it has been done by others, but it seems worth while to give it a wider notice.

\section{Technique}

(1) Pantocain anaesthesia of conjunctival sac. Injection of $2.3 \mathrm{ml}$. novocainadrenalin is made under the skin and as deeply as possible into the upper eyelid from the outside. Care must be taken to inject sufficiently far nasally and temporally. If necessary and especially when the operation is performed by an inexperienced person a hornplate is inserted under the eyelid to protect the eyeball.

(2) Three sutures are inserted into and parallel to the margin of the eyelid, one in the middle and the others between the 1st and 2nd, and 3rd and 4th, quarters, respectively of the length of the eyelid. The hornplate is then changed

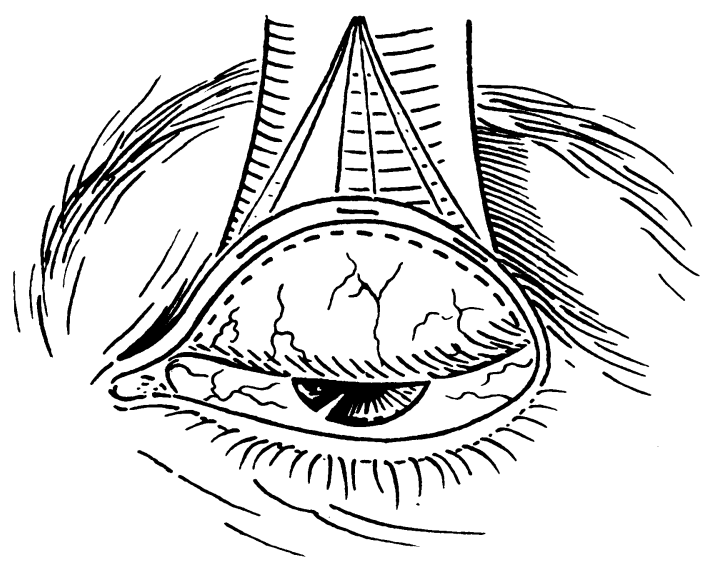

FIG. 1.-Everted position of eyelid. over to the outside, and by means of the three sutures the whole eyelid is everted over the plate and kept in this position by an assistant. (Fig. 1)

(3) An incision is then made $2-3 \mathrm{~mm}$. from and parallel to the margin of the lid on the conjunctival side. The incision goes through the conjunctiva and the thickness of whole tarsus. It is important to make the cut surface parallel to the end of the tarsal plate (Fig. 3). The incision is carried well out to the corners of the margin. At the inner end there is usually bleeding from an artery, which it is advisable to stop with a catgut ligature. In performing this incision it is very interesting in many cases to see how thick the tarsus is and how detritus and pus are coming from the incised Gl. Meibomi. It seems that these glands play an important part in maintaining trachoma as they are inaccessible to treatment from outside.

(4) After the incision is made, the outside of the proximal part of the tarsus is very easily dissected free to an extent of $2-3 \mathrm{~mm}$. Then the anterior surface of the distal tarsus fragment has to be dissected away just down to the eye-lashes which may then be seen in the bottom of the wound. This is best performed with a pair of curved eye-scissors and a big-toothed forceps. The eye-lashes must not be damaged. Now the distal tarsus fragment is readily movable and can be turned 


\section{ENTROPION IN TRACHOMA}

$90^{\circ}$ outwards. If it is still fixed, however, a small incision is made with a pair of scissors as far temporally as possible and under the skin perpendicularly to the margin. Care must be taken not to make this incision too large, and to avoid incising the skin, which would be even worse as it would cause deformation later.

(5) The correct application of the sutures is the most important part of the whole operation. Usually six double-armed sutures must be used; these have to be inserted-two to each place-in the middle, and in the border between the 1st and 2 nd and $3 \mathrm{rd}$ and 4 th quarters of the length of the eyelid. It is advisable to start with the middle sutures. The needle is introduced into the conjunctival side of the proximal tarsus about 1-2 $\mathrm{mm}$. from the incision and then carried out in the middle of the thickness of tarsus (the cut surface). From there it is carried through the former outer surface of the distal part of the tarsus as far down as possible and out among the eye-lashes or as near them as possible in the very margin. The same method is adopted for the other needle of the suture, which has to be placed $2-3 \mathrm{~mm}$. from the side of the other. Before tying these sutures we have to insert another double-armed suture $2 \mathrm{~mm}$. above the first. The needle is inserted perpendicularly through the whole tarsus, then it is passed down in the edge between the former anterior surface of the distal tarsus-part and the skin, and goes through the skin just above the eye-lashes. The same is done with the other needle 2-3 mm. towards the side (Fig. 4).

The object of the first suture is to attach the former anterior surface of the distal part of the tarsus to the cut surface of the proximal part of tarsus, thus turning the distal tarsus fragment $90^{\circ}$ outwards; the object of the second suture is to secure the distal part in position and if possible to increase the exersion and also to fix the skin just above the lowest part of the tarsus to the outer edge of the proximal part of the tarsus (Fig. 4). The suture inserted last may be tied before the first one. After this the four other sutures are inserted in the same way as described above.

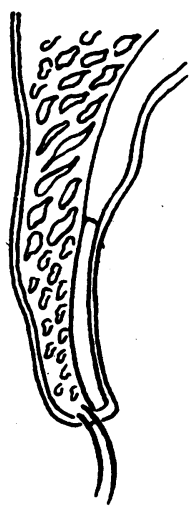

Fig. 2.-Before operation.

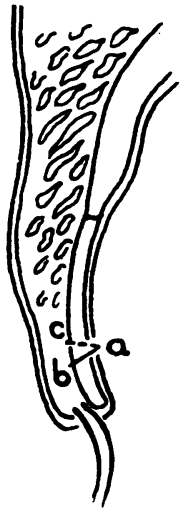

FIG. 3.-Incision.

$$
a-b=\text { correct. }
$$$$
\mathrm{a}-\mathrm{c}=\text { wrong. }
$$

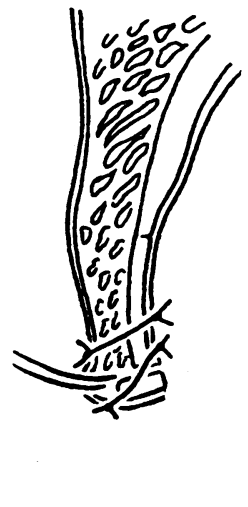

FIG. 4.-Sutures

in place.

(6) The patient is given a bandage with vaseline or sulphonamide ointment over both eyes (both eyes can be treated at the same time), the bandage is removed the next day and the patient given coloured glasses to protect the eyes. Because of the conjunctival infection it is not advisable to use a bandage for more than one day. On the 1 st or 2 nd day after the operation there may be swelling of the eyelids, which disappears without complications. The stitches are taken out on the 5 th or 6 th day. It is rather difficult to remove the stitches, but this must be carefully done as otherwise infection may ensue. (The only complication I have seen in the post-operative period or later is a few cases of polyp.) 
This operation may sound complicated in words, but is in fact readily done. I have even trained some unskilled dressers to do it, because of the enormous number of cases and the shortage of doctors-and they learned it quickly and are doing it well. With practice the operation may be performed in $30-35$ minutes.

The results are very encouraging, as far as can be judged. A complete "follow up", of all cases is not possible in this country, but it may be supposed that most if not all of the patients with relapses will come back. Up till now (November, 1949) 386 operations have been performed, 163 by myself, 90 by my assistant, and 133 by a dresser (each case operated means one eyelid).

My own $16: 3$ cases (operated in 1946-48) I divide into the following groups :

(1) 22 cases, which were operated in the beginning in a slightly different way, the tarsal conjunctiva by the original method of Blaskowicz (without inversion of the tarsus) was dissected free 5-6 mm. from the tarsus. They showed good results in twenty operations, which were controlled as follows: after 1 week, ten cases; 1-2 weeks, one case; $2-3$ weeks, seven cases; 2 years, two cases.

Two cases (both in the same patient) showed relapse after 11 days, the entropion was reduced.

(2) 141 cases showed good results in 137 cases, and were controlled as follows :

$$
\begin{array}{cccccr}
\text { After } & 1 & \text { week } & . . & \ldots & 18 \\
, " & 1-2 & \text { weeks } & \ldots & 16 \\
., & 2-3 & , & \ldots & 10 \\
, & 3-4 & , & \ldots & 4 \\
, & 1-3 & \text { months } & \ldots & 34
\end{array}
$$

After 3-6 months ... ... ... 24

$\begin{array}{llllll}, & 6-9 \quad, \quad \ldots & \ldots & \ldots & 11\end{array}$

$\begin{array}{llllll}, & 9-12 \quad, & \ldots & \ldots & \ldots & 9\end{array}$

$\begin{array}{llllll}, 14-16 \quad, \quad \ldots & \ldots & \ldots & 6\end{array}$

," $16-18 \quad, \quad \ldots \quad \ldots \quad \ldots \quad 5$

Four cases failed to give perfect results; the entropion was cured but the trichiasis remained: after 6 months one case had two eyehairs towards the cornea, and after 17 months one case had three eyehairs towards the cornea.

Two cases (both in the same patient) showed a relapse after 6 weeks, but it must be observed that this case had previously been operated by an Abyssinian "doctor" with removal of the greater part of the matrix ciliarum, which made the operation more difficult. Similar cases, however, have been operated with good results.

(3) The other 223 operations have not yet been studied, owing to the short time that has passed since the operation, but the immediate result has been good in all.

\section{Summary}

Trachoma is a very common disease in Ethiopia, and in the Ophthalmic Clinic 20 per cent. of cases also show entropion of the upper evelid.

A method of operating for entropion is described, the results being good. Out of 165 operations, $15 \%$ were completely satisfactory, and the remaining six showed a residual trichiasis, the entropion being corrected. 